\title{
PEMETAAN POTENSI BAHAYA BANJIR DI KABUPATEN MANOKWARI MELALUI PEMANFAATAN DATA GLOBAL PRECIPITATION MEASUREMENT (GPM) DAN ANALISIS BENTANG LAHAN
}

\author{
FLOODS HAZARD MAPPING IN MANOKWARI USING GLOBAL \\ PRECIPITATION MEASURMENT (GPM) AND LANDSCAPE ANALYSIS \\ METHOD
}

\author{
Arif Faisol $^{1 \bowtie}$, Budiyono ${ }^{2}$, Indarto Indarto ${ }^{3}$, Elida Novita $^{3}$ \\ ${ }^{1}$ Fakultas Teknologi Pertanian - Universitas Papua \\ ${ }^{2}$ Fakultas Pertanian - Universitas Papua \\ ${ }^{3}$ Fakultas Teknologi Pertanian - Universitas Jember \\ $\bowtie$ Komunikasi Penulis, email: arif.unipa@gmail.com \\ DOI:http://dx.doi.org/10.23960/jtep-lv9i2.96-103
}

Naskah ini diterima pada 6 Februari 2020; revisi pada 27 Mei 2020;

disetujui untuk dipublikasikan pada 5 Juni 2020

\begin{abstract}
Rainfall data is the main parameter in flood analysis. The limited number of climate stations and rain stations in Manokwari due to low spatial representativeness of rainfall. This study aims to utilize Global Precipitation Measurement (GPM) as a satellite-based rainfall observer to analyze and floods hazard mapping in Manokwari. The method used in this research is landscape analysis. Research showed that almost all areas in Manokwari had high levels of flood hazard at any period except Tanah Rubuh district.
\end{abstract}

Keywords: flood, GPM, landscape analysis, rainfall

\begin{abstract}
ABSTRAK
Data hujan merupakan parameter utama dalam analisis banjir. Terbatasnya jumlah stasiun iklim dan stasiun hujan di Kabupaten Manokwari mengakibatkan tingkat keterwakilan spasial data hujan di Kabupaten Manokwari menjadi sangat rendah. Penelitian ini bertujuan memanfaatkan data Global Precipitation Measurement (GPM) yang merupakan pengamat curah hujan berbasis satelit untuk menganalisis dan memetakan potensi banjir di Kabupaten Manokwari. Metode yang digunakan dalam penelitian ini adalah analisis bentang lahan (landscape analysis). Hasil penelitian menunjukkan bahwa hampir semua wilayah di Kabupaten Manokwari memiliki tingkat kerawanan banjir tinggi pada berbagai periode ulang kecuali Distrik Tanah Rubuh.
\end{abstract}

Kata Kunci: analisis bentang lahan, banjir, GPM, hujan

\section{PENDAHULUAN}

Banjir merupakan salah satu bencana alam di Kabupaten Manokwari. Pada akhir tahun 2019 tepatnya pada tanggal 27 Desember 2019 rumah warga di kampung Aurmios dan kampung Manggupi - Distrik Sidey terendam banjir setinggi 1 meter yang dipicu oleh intensitas hujan selama 6 jam. Berdasarkan data dari stasiun meteorologi Rendani, curah hujan di Kabupaten Manokwari pada saat kejadiaan banjir cukup besar mencapai 50,5 $\mathrm{mm}$. Sebelumnya pada tahun 2018 tepatnya pada tanggal 6 Februari dan 30 April Kabupaten Manokwari mengalami banjir akibat intensitas hujan selama hampir 4 jam dengan curah hujan sebesar $23 \mathrm{~mm}$ pada 6 Februari dan 27 mm pada 30 April. Berdasarkan data dari Badan Nasional Penanggulangan Bencana (BNPB) pada kurun 2011 - 2019 telah terjadi kejadian banjir sebanyak 10 kali di Kabupaten Manokwari (Badan Nasional Penanggulangan Bencana, 2020) dengan periode kejadian 1 - 2 tahun. 
Informasi curah hujan merupakan informasi yang sangat penting dalam pemetaan bahaya banjir di Kabupaten Manokwari. Terbatasnya jumlah stasiun hujan dan stasiun klimatologi dengan kerapatan $\pm 354 \mathrm{~km}^{2} /$ stasiun hujan serta penyebaran yang tidak merata di Kabupaten Manokwari mengakibatkan tingkat keterwakilan spasial data hujan sangat rendah. Distribusi stasiun iklim dan stasiun hujan di Kabupaten Manokwari disajikan pada Gambar 1.

Global Precipitation Measurement (GPM) merupakan pengamat curah hujan berbasis satelit yang memiliki kemampuan melakukan perekaman data hujan diseluruh dunia setiap 2 4 jam perhari serta memiliki resolusi spasial 10 km (Goddard Space Flight Center, 2013). Sejumlah penelitian didunia menunjukkan bahwa data hujan GPM memiliki akurasi yang cukup baik dibanding data hujan hasil pengamatan, diantaranya penelitian yang dilakukan oleh Azka et al. (2018), Verma dan Ghosh (2018), Sun et al. (2018), Sungmin et al. (2017), Asong et al. (2017), Omranian et al.
(2018), Ma et al. (2016), Chen et al. (2016), Xu et al. (2017), Sharifi et al. (2016), dan Gaona et al. (2016). Hasil penelitian terdahulu juga menunjukkan bahwa data GPM memiliki penyimpangan sebesar $28 \%$ atau akurasi sebesar 72\% dibanding data hujan hasil pengukuran pada stasiun iklim di Kabupaten Manokwari (Faisol etal., 2019).

Analisis bentang lahan (landscape analysis) merupakan salah satu metode untuk memetakan potensi bahaya banjir dengan menggabungkan parameter fisik permukaan lahan yaitu tutupan lahan (land cover) dan topografi, serta parameter iklim yaitu hujan. Analisis bentang lahan merupakan metode standard yang ditetapkan oleh Badan Standarisasi Nasional (BSN) dalam penyusunan peta rawan banjir yang tertuang dalam SNI 8197:2015 (Badan Standardisasi Nasional, 2015). Nisato menggunakan analisis bentang lahan untuk memetakan kerawanan banjir disekitar Daerah Aliran Sungai (DAS) Tangka - Sulawesi Selatan (Nisarto, 2016), Nurdin dan Fakhri menggunakan metode bentang lahan untuk

Tabel 1. Kejadian Banjir di Kabupaten Manokwari

\begin{tabular}{cccc}
\hline Tahun & $\begin{array}{c}\text { Jumlah Kejadian } \\
\text { Banjir }\end{array}$ & $\begin{array}{c}\text { Korban Jiwa } \\
\text { (mengungsi) }\end{array}$ & $\begin{array}{c}\text { Rumah Terendam } \\
\text { (unit) }\end{array}$ \\
\hline 2011 & 1 & 250 & 50 \\
2013 & 1 & 85 & 70 \\
2014 & 1 & 456 & 120 \\
2016 & 1 & 35 & - \\
2018 & 2 & 441 & 839 \\
2019 & 4 & - & 168 \\
\hline
\end{tabular}

(Sumber : Badan Nasional Penanggulangan Bencana, 2020)

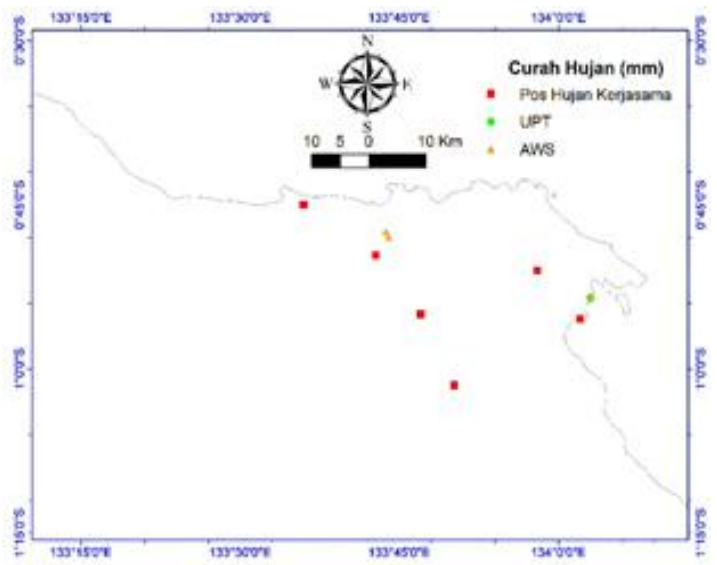

Gambar 1. Distribusi Stasiun Hujan dan Stasiun Iklim di Kabupaten Manokwari (Badan Meteorologi Klimatologi dan Geofisika, 2018) 
menganalisis tingkat kerawanan banjir di Kabupaten Kampar - Riau (Nurdin \& Fakhri, 2017). Beberapa penelitian lain tentang pemetaan rawan banjir menggunakan analisis bentang lahan antara lain dilakukan oleh Haryani (2017), Anwari dan Makruf (2019), Yetty et al. (2018), dan Kuswadi et al. (2014).

Berdasarkan kondisi di atas, penelitian ini bertujuan untuk mengaplikasikan data GPM untuk memetakan potensi bahaya banjir di Kabupaten Manokwari menggunakan analisis bentang lahan.

\section{BAHAN DAN METODA}

Penelitian ini dilakukan di Kabupaten Manokwari - Provinsi Papua Barat pada bulan Januari hingga Februari tahun 2020. Secara garis besar penelitian ini terdiri atas 3 (tiga) tahapan utama, yaitu; inventarisasi data, analisis data, dan interpretasi dalam bentuk peta tematik. Untuk lebih jelasnya lokasi dan tahapan penelitian disajikan pada Gambar 2.

\subsection{Inventarisasi Data}

Pada tahap ini dilakukan pengumpulan data; GPM harian kawasan Manokwari perekaman 2014 -
2019, peta tutupan lahan, dan peta topografi dalam format Digital Elevation Models (DEM). Data GPM diperoleh dari situs https:// disc.gsfc.nasa.gov/, sedangkan peta tutupan lahan dan peta topografi dalam format DEM dapat diperoleh melalui situs http:// tanahair.indonesia.go.id/portal-web.

\subsection{Analisis Data}

Pada tahap ini dilakukan analisis hujan rencana pada beberapa periode ulang menggunakan data GPM dan analisis banjir menggunakan metode bentang lahan (landscape analysis).

\subsubsection{Analisis Hujan Rencana}

Curah hujan rencana dianalisis menggunakan metode Distribusi Normal dengan Persamaan 1.

$$
X_{T}=\bar{X}+K_{T} * S
$$

Dimana, $\mathrm{X}_{\mathrm{T}}$ adalah curah hujan rencana pada periode ulang T-tahun, $\bar{X}$ adalah curah hujan rerata, $\mathrm{K}_{\mathrm{T}}$ adalah faktor probabilitas, dan $\mathrm{S}$ adalah Simpangan baku data hujan.

\subsubsection{Analisis Bentang Lahan}

Analisis bentang lahan merupakan metode standard dalam penyusunan peta rawan banjir yang menggabungkan aspek fisik lahan yang

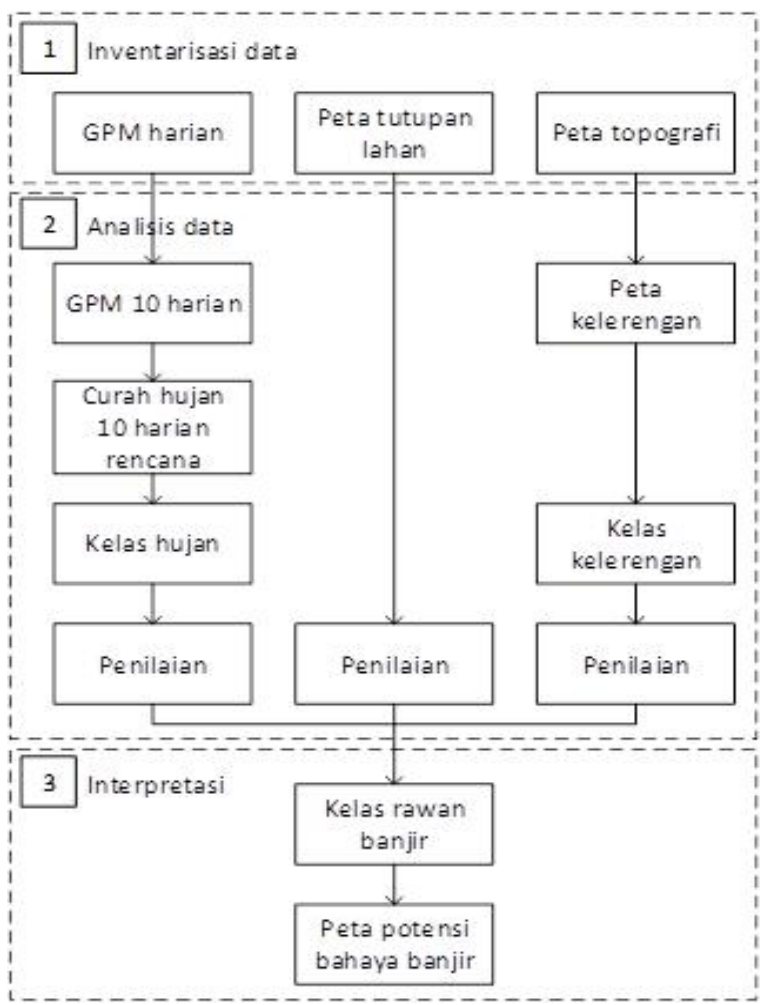

Gambar 2. Diagram Alir Penelitian 
meliputi tutupan lahan dan topografi, serta aspek iklim yaitu hujan dengan metode skoring. Skoring dan pembobotan dari parameter tersebut disajikan pada Tabel 3, Tabel 4, dan Tabel 5. Kelas rawan bajir dihitung berdasarkan penjumlahan dari ketiga parameter diatas dengan kriteria seperti pada Tabel 6.

\subsection{Interpretasi}

Pada tahapan ini dilakukan penyajian potensi bahaya banjir di Kabupaten Manokwari pada berbagai periode ulang dalam bentuk peta tematik.

Tabel 2. Faktor Probabilitas pada Distribusi Normal

\begin{tabular}{cccc}
\hline No. & Periode Ulang (T) tahun & Peluang & Faktor Probabilitas $\left(\mathbf{K}_{\mathbf{T}}\right)$ \\
\hline 1 & 1.00 & 0.99 & -3.05 \\
2 & 1.25 & 0.80 & -0.84 \\
3 & 1.67 & 0.60 & -0.25 \\
4 & 2.00 & 0.50 & 0 \\
5 & 2.50 & 0.40 & 0.25 \\
6 & 5.00 & 0.20 & 0.84 \\
7 & 10.00 & 0.10 & 1.28 \\
8 & 20.00 & 0.05 & 1.64 \\
9 & 50.00 & 0.02 & 2.05 \\
10 & 100.00 & 0.01 & 2.33 \\
\hline
\end{tabular}

Tabel 3. Skoring dan Pembobotan Curah Hujan

\begin{tabular}{cccc}
\hline Curah Hujan 10 Harian & Skoring & Bobot & Nilai \\
\hline$=200 \mathrm{~mm}$ & 3 & 0.3 & 0.9 \\
$50-200 \mathrm{~mm}$ & 2 & 0.3 & 0.6 \\
$=50 \mathrm{~mm}$ & 1 & 0.3 & 0.3 \\
\hline
\end{tabular}

(Sumber: Badan Standardisasi Nasional, 2015)

Tabel 4. Skoring dan Pembobotan Penutup Lahan

\begin{tabular}{lccc}
\hline Penutup lahan & Skoring & Bobot & Nilai \\
\hline Permukiman & 3 & 0.35 & 1.05 \\
Semak/ Pertanian & 2 & 0.35 & 0.70 \\
Sawah/ Hutan & 1 & 0.35 & 0.35 \\
\hline
\end{tabular}

(Sumber: Badan Standardisasi Nasional, 2015)

Tabel 5. Skoring dan Pembobotan Topografi

\begin{tabular}{cccc}
\hline Kelerengan & Skoring & Bobot & Nilai \\
\hline $0 \%-2 \%$ & 3 & 0.35 & 1.05 \\
$2 \%-4 \%$ & 2 & 0.35 & 0.70 \\
$>4 \%$ & 1 & 0.35 & 0.35 \\
\hline
\end{tabular}

(Sumber: Badan Standardisasi Nasional, 2015)

Tabel 6. Kelas Rawan Banjir

\begin{tabular}{cc}
\hline Interval & Kelas rawan banjir \\
\hline $2.1-3.0$ & Tinggi \\
$1.1-2.0$ & Menengah \\
$0.1-1.0$ & Rendah \\
\hline
\end{tabular}

(Sumber: Badan Standardisasi Nasional, 2015) 


\section{HASIL DAN PEMBAHASAN}

Secara umum Kabupaten Manokwari memiliki curah hujan yang cukup tinggi sepanjang tahun. Berdasarkan analisis data GPM perekaman 1 Juni 2014 - 30 September 2019 curah hujan dasarian rerata di Kabupaten Manokwari sekitar 95,61 $\mathrm{mm}-161,12 \mathrm{~mm}$ atau sekitar 9,56 $\mathrm{mm} /$ hari $16,11 \mathrm{~mm} /$ hari. Distribusi curah hujan di Kabupaten Manokwari berdasarkan analisis data GPM disajikan pada Gambar 3.

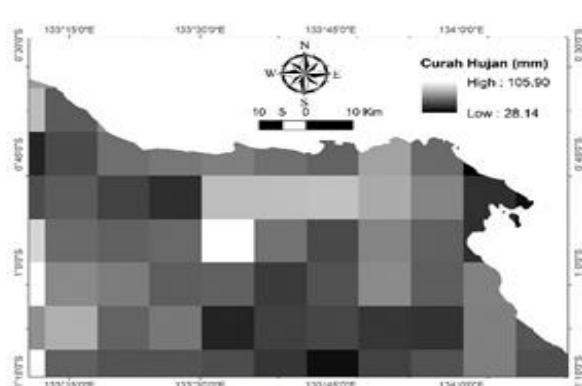

(a)

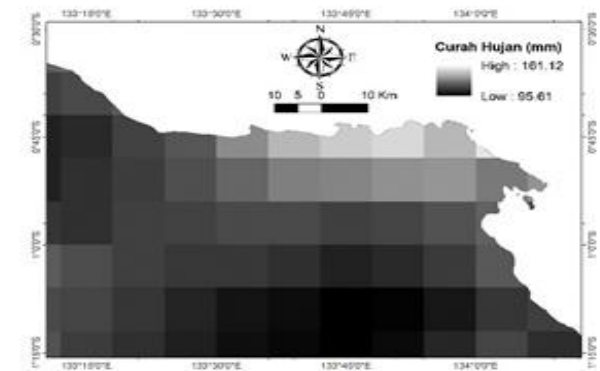

(b)

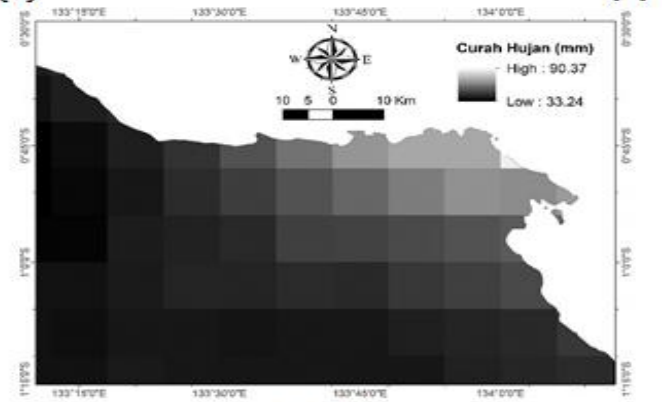

(c)

Gambar 3. Distribusi Curah Hujan Dasarian di Kabupaten Manokwari Berdasarkan Data GPM: (a) Perekaman 21 - 30 September 2019, (b) Rerata Berdasarkan Perekaman 1 Juni 2014 - 30 September 2019, (c) Simpangan Baku Berdasarkan Perekaman 1 Juni 2014 - 30 September 2019

(Sumber: Analisis, 2019)

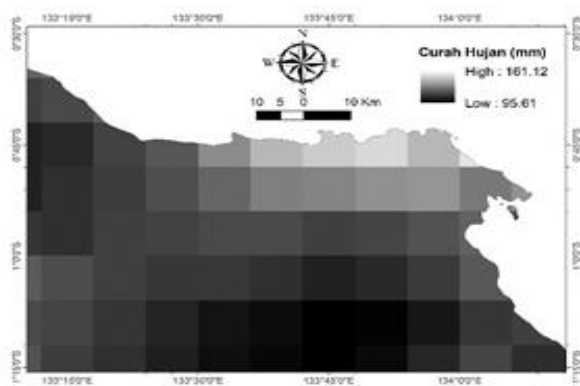

(a)

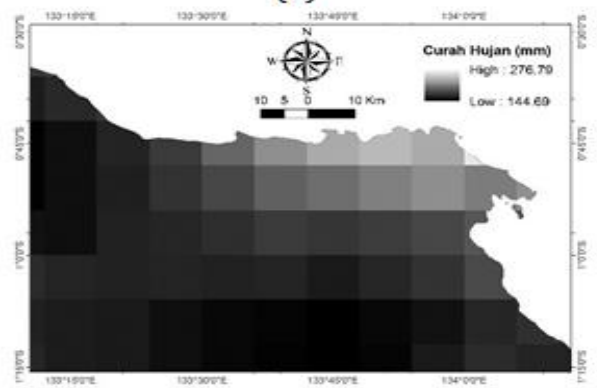

(c)

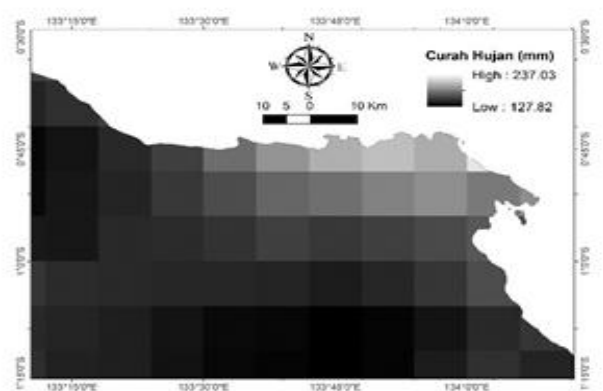

(b)

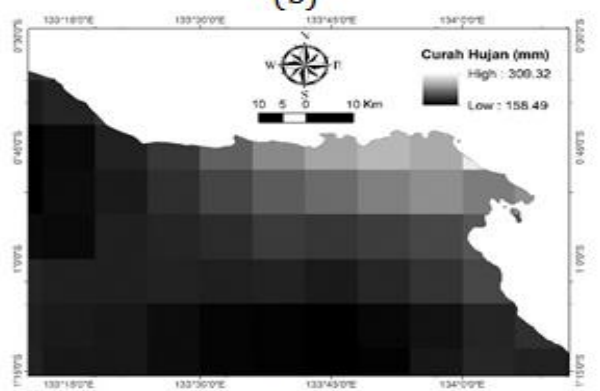

(d)

Gambar 4. Distribusi Curah Hujan Rencana di Kabupaten Manokwari: (a) Periode Ulang 2 Tahun, (b)

Periode Ulang 5 Tahun, (c) Periode Ulang 10 Tahun, (d) Periode Ulang 20 Tahun (Sumber: Analisis, 2019) 
Adapun hujan dasarian rencana di Kabupaten Manokwari sekitar $95.61 \mathrm{~mm}$ - $161.12 \mathrm{~mm}$ pada periode ulang 2 tahun, $127.82 \mathrm{~mm}-237.03 \mathrm{~mm}$ pada periode ulang 5 tahun, $144.69 \mathrm{~mm}-276.79$ $\mathrm{mm}$ pada periode ulang 10 tahun, dan $158.49 \mathrm{~mm}$
- $309.32 \mathrm{~mm}$ pada periode ulang 20 tahun. Distribusi curah hujan dasarian rencana di Kabupaten Manokwari berdasarkan analisis data GPM dan metode distribusi distribusi normal disajikan pada Gambar 4.

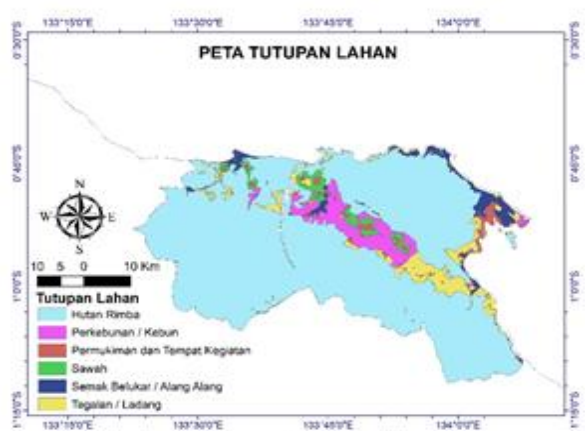

(a)

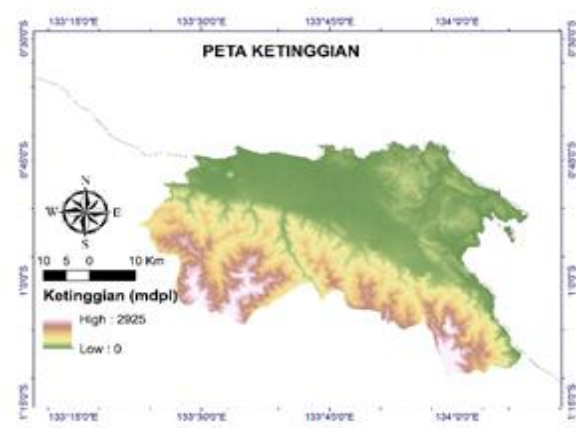

(b)

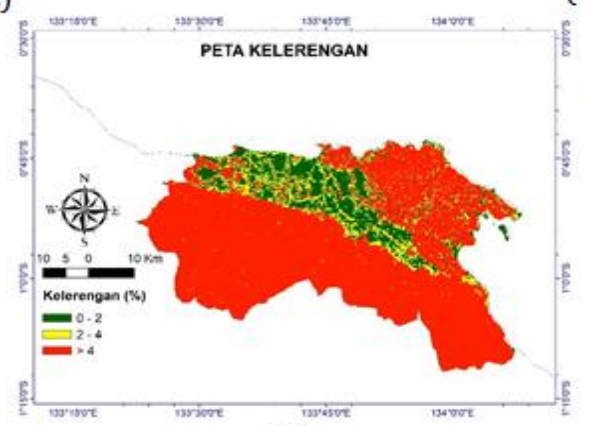

(c)

Gambar 5. Kondisi Lahan di Kabupaten Manokwari: (a) Tutupan Lahan, (b) Ketinggian, (c) Kelerengan

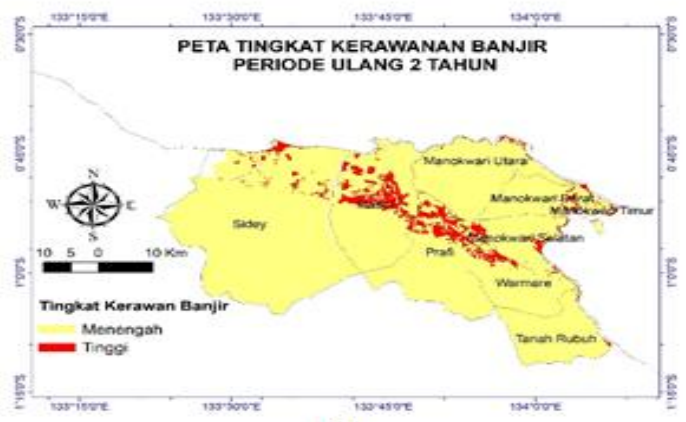

(a)

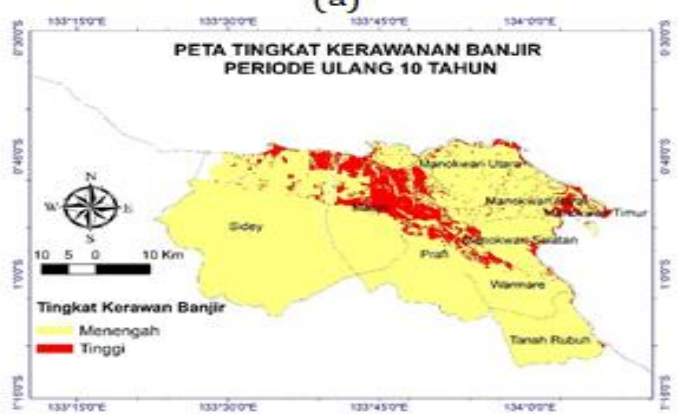

(c)

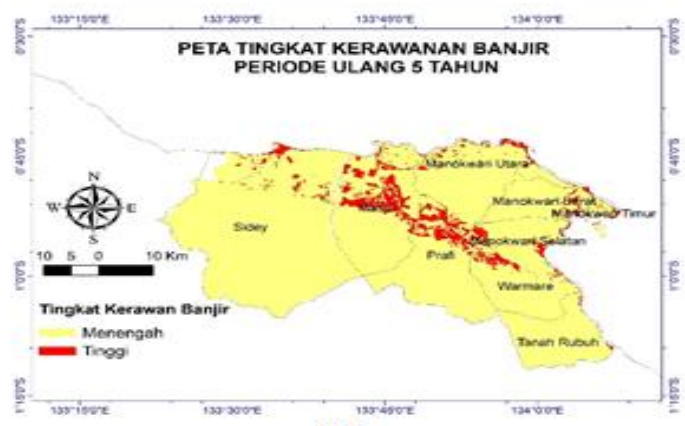

(b)

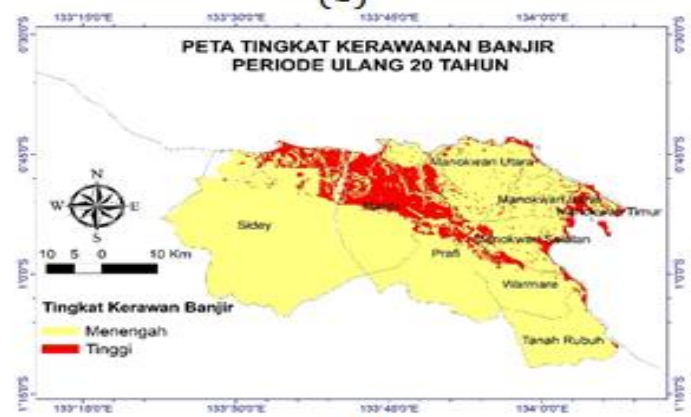

(d)

Gambar 6. Peta Tingkat Kerawanan Banjir di Kabupaten Manokwari: (a) Periode Ulang 2 Tahun, (b) Periode Ulang 5 Tahun, (c) Periode Ulang 10 Tahun, (d) Periode Ulang 20 Tahun (Sumber: Analisis, 2019) 
Berdasarkan interpretasi peta Rupa Bumi Indonesia yang dirilis Badan Informasi Geospasial (BIG), penutupan lahan di Kabupaten Manokwari didominasi oleh kawasan hutan, perkebunan, dan ladang. Sedangkan ditinjau dari segi topografi, Kabupaten Manokwari didominasi oleh dataran rendah (ketinggian $<700$ mdpl) serta didominasi oleh kelerengan datar dan bergelombang. Kondisi fisik lahan Kabupaten Manokwari disajikan pada Gambar 5.

Dari hasil analisis bentang lahan, hampir semua wilayah di Kabupaten Manokwari memiliki tingkat kerawanan banjir tinggi pada berbagai periode ulang, kecuali Distrik Tanah Rubuh yang memiliki tingkat kerawanan sedang. Hal ini sesuai dengan laporan dari Badan Nasional Penanggulangan Bencana (BNPB) bahwa periode kejadian banjir di Kabupaten Manokwari setiap 1 - 2 tahun pada kurun 2011 - 2019. Tingginya curah hujan di Kabupaten Manokwari menjadi faktor utama tingginya kerawanan banjir di Kabupaten Manokwari. Tingkat kerawanan banjir di Kabupaten Manokwari berdasarkan analisis GPM dan bentang lahan disajikan pada Gambar 6 .

\section{KESIMPULAN DAN SARAN}

Data GPM dan analisis bentang lahan dapat menggambarkan potensi bahaya banjir di Kabupaten Manokwari dengan cukup baik dibandingkan dengan kejadian sebenarnya. Namun masih perlu divalidasi dengan pengecekan dilapangan (ground cek) pada wilayah terdampak bencana banjir. Disamping itu penelitian ini perlu dilakukan didaerah lain untuk mengetahui kinerja data GPM dan analisis bentang lahan dalam memetakan bahaya banjir.

\section{DAFTAR PUSTAKA}

Anwari, \& Makruf, M. (2019). Pemetaan Wilayah Rawan Bahaya Banjir di Kabupaten Pamekasan Berbasis Sistem Informasi Geografis (SIG). Jurnal Ilmiah NERO, 4(2), 117-123.

Asong, Z. E., Razavi, S., Wheater, H. S., \& Wong, J. (2017). Evaluation of Integrated
Multisatellite Retrievals for GPM ( IMERG ) over Southern Canada against Ground Precipitation Observations/ : A Preliminary Assessment. Journal of Hydrometeorology, 18, 1033-1050. https:/ /doi.org/10.1175/JHM-D-16-0187.1

Azka, M. A., Sugianto, P. A., Silitonga, A. K., \& Nugraheni, I. R. (2018). Uji Akurasi Produk Estimasi Curah Hujan Satelit GPM IMERG di Surabaya, Indonesia. Jurnal Sains \& Teknologi Modifikasi Cuaca, 19(2), 83-88.

Badan Meteorologi Klimatologi dan Geofisika. (2018). Metadata Stasiun. Retrieved February 28, 2018, from https:// dataonline.bmkg.go.id/home

Badan Nasional Penanggulangan Bencana. (2020). Bencana Menurut Wilayah Kabupaten/ Kota. Retrieved February 6, 2020, from http://bnpb.cloud/dibi/ tabel2a

Badan Standardisasi Nasional. (2015). Metode Pemetaan Rawan Banjir Skala 1:50.000 dan 1:25.000 (1st ed.). Jakarta: Badan Standardisasi Nasional.

Chen, Z., Qin, Y., Shen, Y., \& Zhang, S. (2016). Evaluation of Global Satellite Mapping of Precipitation Project Daily Precipitation Estimates over the Chinese Mainland. Advances in Meteorology, 2016, 15. https:/ /doi.org/http://dx.doi.org/10.1155/2016/ 9365294

Faisol, A., Budiyono, B., Indarto, I., \& Novita, E. (2019). Evaluasi Data Hujan Harian Global Precipitation Measurement (GPM) versi ke-6 di Provinsi Papua Barat. Seminar Nasional MIPA UNIPA IV Tahun 2019, 147154. Retrieved from https:// prosiding.fmipa.unipa.ac.id/index.php/ SNMIPAUNIPA/article/download/40/31

Gaona, M. F. R., Overeem, A., Leijnse, H., \& Uijlenhoet, R. (2016). First-Year Evaluation of GPM Rainfall over the Netherlands/ : IMERG Day 1 Final Run ( V03D ). American Meteorological Society, 2016, 2799-2814. 
https://doi.org/10.1175/JHM-D-160087.1

Goddard Space Flight Center. (2013). Global Precipitation Measurement (GPM) Science Implementation Plan. Greenbelt: NASA.

Haryani, N. S. (2017). Analisis Zona Potensi Rawan Banjir Menggunakan Data Penginderaan Jauh dan SIG di Kalimantan Timur. Seminar Nasional Penginderaan Jauh Ke-4, 517-524.

Kuswadi, D., Zulkarnain, I., \& Suprapto. (2014). Identifikasi Wilayah Rawan Banjir Kota Bandar Lampung Dengan Aplikasi Sistem Informasi Geografis ( SIG ). Jurnal Ilmiah Teknik Pertanian, 6(1), 22-33.

Ma, Y., Tang, G., Long, D., Yong, B., Zhong, L., Wan, W., \& Hong, Y. (2016). Similarity and Error Intercomparison of the GPM and Its Predecessor-TRMM Multisatellite Precipitation Analysis Using the Best Available Hourly Gauge Network over the Tibetan Plateau. Remote Sensing, 8(569), 1-17. https://doi.org/10.3390/rs8070569

Nisarto, F. (2016). Pemetaan Kerawanan Banjir Daerah Aliran Sungai Tangka. Universitas Hasanuddin.

Nurdin, \& Fakhri. (2017). Analisa Kawasan Rawan Banjir di Kabupaten Kampar Menggunakan Aplikasi Sistem Informasi Geografis. Seminar Nasional Pelestarian Lingkungan (SENPLING), 431-438.

Omranian, E., Sharif, H. O., \& Tvakoly, A. A. (2018). How Well Can Global Precipitation Measurement ( GPM) Capture Hurricanes/ ? Case Study/ : Hurricane Harvey. Remote Sensing, 14. https://doi.org/10.3390/ rs10071150
Sharifi, E., Steinacker, R., \& Saghafian, B. (2016). Assessment of GPM-IMERG and Other Precipitation Products against Gauge Data under Different Topographic and Climatic Conditions in Iran/ : Preliminary Results. Remote Sensing, 8(135), 24. https:// doi.org/10.3390/rs8020135

Sun, W., Sun, Y., Li, X., Wang, T., Wang, Y., Qiu, Q., \& Deng, Z. (2018). Evaluation and Correction of GPM IMERG Precipitation Products over the Capital Circle in Northeast China at Multiple Spatiotemporal Scales. Advances in Meteorology, 2018, 14 pages.

Sungmin, O., Foelsche, U., Kirchengast, G., Fuchsberger, J., Tan, J., \& Petersen, W. A. (2017). Evaluation of GPM IMERG Early , Late, and Final rainfall estimates using WegenerNet gauge data in southeastern Austria. Hydrology and Earth System Science, 21, 6559-6572.

Verma, P., \& Ghosh, S. K. (2018). Study of GPMIMERG Rainfall Data Product for Gangotri Glacier. The International Archives of the Photogrammetry, Remote Sensing and Spatial Information Sciences, XLII(November), 20-23. Dehradun.

Xu, R., Tian, F., Yang, L., Hu, H., Lu, H., \& Hou, A. (2017). Ground validation of GPM IMERG and TRMM 3B42V7 rainfall products over southern Tibetan Plateau based on a high-density rain gauge network. Journal of Geophysical Research, 910-924. https://doi.org/ 10.1002/2016JD025418

Yetty, S., Edial, H., \& Triyatno. (2018). Pemetaan Wilayah Bahaya Banjir di Kota Sungai Penuh. Jurnal Buana, 2(5), 383391. 